\title{
Factors of future teachers' motivation formation for the physical improvement
}

Authors' Contribution:

A Study Design

B Data Collection

C Statistical Analysis

D Data Interpreta

E Manuscript Preparation

F Literature Search

G Funds Collection

\author{
Anna Hakman ${ }^{1}$ ACG, Olena Andrieieva ${ }^{2 B C}$, Vitalii Kashuba2 BF, Halyna Bezverkhnia ${ }^{3}$ AG, \\ Viktoria Tsybulska ${ }^{4 \mathrm{CDE}}$, Mykola Maievskyi4 EF, Tetiana Osadchenko4 B, Andrii Semenov ${ }^{4 \mathrm{FG}}$, \\ Olena Kljus ${ }^{5 \mathrm{CG}}$, Oksana Tsiuniak ${ }^{6} \mathrm{~F}$, Nataliia Nikula ${ }^{1 \mathrm{~F}}$, Oleksandr Tomenko ${ }^{7 \mathrm{CG}}$ \\ ${ }^{1}$ Yuriy Fedkovych Chernivtsi National University, Chernivtsi, Ukraine \\ ${ }^{2}$ National University of Physical Education and Sport of Ukraine, Kyiv, Ukraine \\ ${ }^{3}$ Lutsk National Technical University, Lutsk, Ukraine \\ ${ }^{4}$ Pavlo Tychyna Uman State Pedagogical University, Uman, Ukraine \\ ${ }^{5}$ Kamianets-Podilsky Ivan Ohienko National University, Kamianets-Podilsky, Ukraine \\ ${ }^{6}$ Vasyl Stefanyk Precarpathian National University, Ivano-Frankivsk, Ukraine \\ ${ }^{7}$ Sumy State Pedagogical University named after AS Makarenko, Sumy, Ukraine
}

The article uses factor analysis to obtain an insight into the peculiarities of the motivation for physical improvement of students from the Faculty of Primary Education with different modes of attendance.

Material and methods:

Analysis and synthesis of references, surveying, psychological testing, pedagogical experiment, and methods of mathematical statistics were applied. The study involved 173 female students (18-22 years of age) of pedagogical profile with full- and part-time attendance.

Results: The survey highlighted the motivational factors that affect the involvement of female students of pedagogical profile in physical improvement. The motivational factors for second- and fourth-year female students with full- and part-time attendance were emphasized separately. Based on the aforementioned data, factor analysis was conducted involving the abovementioned indicators.

Conclusions: The data of the conducted study on the involvement of female students from the Faculty of Primary Education indicate that second- and fourth-year full-time female students have the motivation for "acquiring knowledge" and that for "mastering a profession". By contrast, second- and fourth-year part-time female students demonstrate the motivation for "mastering a profession". For fourth-year full-time female students, the difference in the motivations for "acquiring knowledge" and "mastering a profession.

Key words: motivation, future teachers, factors, physical improvement.

\section{article details}

Article statistics: Word count: 4,757; Tables: 1; Figures: 0; References: 30

Received: June 2020; Accepted: September 2021; Published: December 2021

Full-text PDF: http://www.balticsportscience.com

Copyright @ Gdansk University of Physical Education and Sport, Poland

Indexation: Celdes, Clarivate Analytics Emerging Sources Citation Index (ESCI), CNKI Scholar (China National Knowledge Infrastructure), CNPIEC, DOAJ, EBSCO - Central \& Eastern European Academic Source, EBSCO - SPORTDiscus, EBSCO Discovery Service, Google Scholar, Index Copernicus, J-Gate, Naviga (Softweco, Primo Central (ExLibris), ProQuest - Family Health, ProQuest - Health \& Medical Complete, ProQuest - Illustrata: Health Sciences, ProQuest Nursing \& Allied Health Source, Summon (Serials Solutions/ProQuest, TDOne (TDNet), Ulrich's Periodicals Directory/ ulrichsweb, WorldCat (OCLC)

Funding: This research received no specific grant from any funding agency in the public, commercial, or not-for-profit sectors.

Conflict of interests: Corresponding author:

Open Access License:
Authors have declared that no competing interest exists.

Anna Hakman; Yuriy Fedkovych Chernivtsi National University, UKRAINE; st. Kotsyubinskogo 2, Chernivtsi, 58012, Ukraine, tel.: +3-8-066-977-73-04, email: an.hakman@chnu.edu.ua

This is an open access article distributed under the terms of the Creative Commons Attribution-Non-Commercial-NoDerivatives 4.0 International (https://creativecommons.org/licenses/by-nc-nd/4.0/), which permits use, distribution, and reproduction in any medium, provided the original work is properly cited, the use is non-commercial and is otherwise in compliance with the license. 


\section{INTRODUCTION}

Training of highly skilled teaching staff is among the highest priorities of national education. A teacher has an important social function to perform: guide the spiritual, mental, physical development and education of an individual. Their work is aimed at organizing not only the educational and cognitive processes, but also the extra-curricular health-promoting activities of students by systematically addressing issues of the formation of an active citizen. Therefore, the principal directions for the development of modern higher education require the search for effective ways of shaping the future teacher's individual physical culture. Physical culture determines the manifestation of moral and volitional qualities and serves as an important means of improving physical, mental and social health. In addition, it is one of the performance indicators of the training process, because the teacher's individual physical culture is projected onto the students and is an example to follow [1-5].

According to researchers [6-9], professional and applied competences of the future teacher should ensure the acquisition of skills and abilities that promote the preservation and strengthening of their own health and their students' health. Furthermore, these skills and abilities should provide general, professional and applied physical training, a certain psychophysical fitness of a graduate of a pedagogical university for the teaching profession, as well as an increase in experience of creative use of physical and sports activities to achieve life goals. Achievement of the accomplishment level in physical culture is characterized by competence, theoretical, practical and methodological proficiency and its influence on the formation of the demand and motivational sphere, physical activity, as well as physical development and physical fitness [3, 10-14]. Hence, the goal of research was to investigate the peculiarities of the motivational sphere for physical improvement of students of the Faculty of Primary Education in various forms of education based on factor analysis.

\section{MATERIALS AND METHODS}

In view of the goal and objectives to be achieved, we used the following research methods: theoretical analysis and synthesis of references, observation, surveying, psychological testing, pedagogical experiment, and methods of mathematical statistics.

Participants of the study. The study was conducted at the Pavlo Tychyna Uman State Pedagogical University at the Faculty of Primary Education. The summative assessment involved 60 full-time female students and 60 part-time female students from the second and fourth year. The formative assessment involved third-year part-time female students: 25 female students in the control group, and 28 female students in the experimental group. All research subjects were females. On average, second-year female students were 18-19 years old, and fourth-year female students were 21-22 years old.

Organization of the study. The surveying method is characterized by the subjects' written answers to standardized questions. This research method was conducted to reveal the students' motivations and interests in physical training and sports, activities in their free time and compliance with the factors of a healthy lifestyle. The survey consisted of three parts: introduction, body and demographic. The body included 30 questions, and the demographic part included 2 questions. Most questions were multiple-choice questions, as well as questions with an "Other" option (16 questions in total). There were 4 open-ended questions that required the respondents' own opinion. In addition, there were 3 dichotomous questions that required Yes/No answers. Three questions were about the value rating, and eight questions dealt with a quality rating from 1 to 10 points.

Psychological methods were used to study the structure and dynamics of motivation of second and fourth year full-time and part-time students of the Faculty of Primary Education. 
"Motivation to study at university" (T. Ilina) is a method consisting of three scales: "Acquisition of knowledge" (desire to acquire knowledge, curiosity), "Mastering a profession" (desire to acquire professional knowledge and form professionally important qualities), "Obtaining a diploma" (desire to obtain a diploma in formal acquisition of knowledge, desire to find workarounds when passing exams and tests). The predominance of motives by the first two scales indicates an adequate student's choice of profession and satisfaction with it.

"Study of the peculiarities of the value orientations' formation" (method of M. Rokych) is a method designed to study the peculiarities of the value orientations' formation. Depending on what specific values are included in the hierarchy of value orientations of the individual, the combination of these values, the degree of their greater or lesser advantage over others, etc., allows determining on what purposes of life the activity of the person is focused, and what means to achieving these goals they prefer. Analysis of the content and hierarchical structure of value orientations also shows the extent to which the identification of students' value orientations meets the public standard and whether they are adequate to the goals of education.

"Motivation for success" (T. Ehlers' method) was used to assess the subsystem of personality orientation of a future specialist. It consists of 41 statements. The respondent must confirm each of the statements with a "yes" or "no" answer.

"Express diagnostics of empathy" (I. Yusupov) is a method consisting of six diagnostic scales of empathy, which express attitudes toward parents, animals, the elderly, children, heroes of works of art, strangers and little-known persons. This questionnaire contains 36 statements. The respondent must answer each of them, using 6 answer options: "I do not know", "sometimes or not", "sometimes", "often", "almost always", "always or yes". Each answer option corresponds to a numerical value: $0,1,2,3,4,5$.

"Self-description of physical development" is a method containing 70 statements that relate to the field of a person's physical development. Respondents can express their attitude to these statements using one of six possible answers: "not true", "mostly not true", "rather not true than true", "rather true than not true", "mostly true", "true". Questionnaire "Selfdescription of physical development" sets 10 indicators of physical development and 1 indicator of general self-esteem: "health", "coordination of movements", "physical activity", "body's slenderness", "athletic abilities", "global physical self", "appearance", "strength", "flexibility", "endurance", "self-esteem".

Statistical analysis. Pearson's correlation coefficient was considered as a measure of the association between variables. In each case, the hypothesis was tested and the value of p-value was calculated. Conclusions are constructed according to the significance level of 0.05. Data were processed using the free and open environment RStudio. To determine the informativeness of psychophysiological factors regarding their influence on the formation of motivation for self-improvement of students, we used factor analysis with varimax rotation with the selection of key components (Kaiser's method). Statistical analysis of the research findings was performed with an error probability of $5 \%$, i.e. the significance level $\alpha=0.05$ $(p<0.05)$ was taken. Mathematical processing was performed on a personal computer IBM Pc-pentium-iv using software packages MS Excel XP, Statistica 10.0, developed by Microsoft, Statsoft (USA).

\section{RESULTS}

To select the most informative indicators of the motivational sphere of female students, including the motivation for success, attitude towards the "physical training" discipline, 
theoretical skills, motivations for studying at the university, empathy and components of physical development self-evaluation, the factor analysis was conducted using varimax rotation and emphasis of prime components. In total, 23 indicators were included with factors that scored at least $6 \%$. For comparison, the factor analysis was conducted separately for second- and fourth-year female student groups with full- and part-time attendance.

We have identified seven factors that affect the formation of indicators for the motivational sphere of second-year female students with full-time attendance.

Almost all indicators of physical development self-evaluation account for the first factor with a dispersion contribution of $27 \%$ with correlation factors ranging from 0.91 (coordination of movements) to 0.54 (health). This indicates a sufficient information value of the "physical development self-evaluation" method in determining the significance of its components for the formation of motivation for physical activities through self-reflection of their physical fitness. The second factor with a dispersion contribution of $10 \%$ comprises two indicators of the overall assessment of attitude towards discipline "physical training" $(r=0.50)$ and its components of the students' theoretical skills assessment $(r=0.66)$, as well as two indicators of empathy for animals and seniors. We interpreted the various components of the indicators of attitude towards physical training, in particular the significance of theoretical skills for professional activities, manifestation of mutual aid, and development of a common culture as a factor of "attitude towards physical training". The third factor with a dispersion contribution of $7 \%$ has two key indicators: the motivation for "mastering a profession" ( $\mathrm{r}$ $=0.89)$ and the motivation for success $(r=0.64)$. Combining these indicators into one factor is quite logical because a high motivation for success gives rise to a high motivation for "mastering a profession". Low rating of the individual components of questions related to the "motivation for success" technique can be a limiting factor in the manifestation of motivation for mastering the professional and applied physical training. We interpreted this factor as the "motivation for mastering professional activities". The fourth factor with a dispersion contribution of $9 \%$ emphasizes the motivation for "acquiring knowledge" $(\mathrm{r}=$ 0.79). This factor also included an indicator of empathy for characters from works of art $(\mathrm{r}=$ 0.74). In our opinion, this is because female students read not only specialist literature but also fiction and emphasize some images that contribute to the motivation for learning this profession. The factor is called the "motivation for acquiring knowledge". The fifth factor (8\%) includes the key indicator of empathy for parents $(r=0.78)$ and self-evaluation of health $(r=0.61)$. We will try to explain their interrelation by the fact that the worse the female students' own health is, the more they depend on their parents, the more they sympathize with their parents and vice versa. We interpreted this factor as the "empathy for parents". The sixth factor (8\%) features a significant indicator of "empathy for strangers and virtual strangers" ( $r=0.87)$. This is clearly due to the fact that second-year female students still find themselves in a state of establishing new contacts due to the relocation because many of them live in dormitories. The seventh factor (6\%) includes two indicators: "empathy for children" ( $r=0.78)$ and "attitude towards discipline of 'physical training'” ( $r=0.51)$, which demonstrates their positive interrelation and importance of physical training classes for the formation of a sensitive and benevolent attitude towards children, who will be the object of their professional activities. The factor is interpreted as the "empathy for children".

The factor structure of the motivational sphere of fourth-year full-time female students has eight main components. The first factor (16\%) includes only five indicators of physical development self-evaluation (the second year students had 10 indicators). The key indicators are overall self-evaluation $(r=0.86)$, self-evaluation of appearance $(r=0.84)$, general physical "me" ( $r=0.83)$, flexibility $(r=0.64)$, and coordination of movements $(r=0.58)$. This clearly indicates the importance of appearance, plasticity and perfection of movements for fourth-year female students, which can serve as a motivation for extracurricular physical 
activities. This factor is called "physical development self-evaluation". The second factor (9\%) distinguishes the "motivation for acquiring knowledge" indicator $(r=0.86)$. This factor also includes indicators of empathy for seniors $(r=0.54)$, characters from works of art $(r=0.57)$ and children $(r=0.72)$. Thus, the motivation for learning facilitates the development of mutual understanding and a benevolent attitude towards children as the object of professional activities. This factor is interpreted as the "motivation for acquiring knowledge". The third factor (8\%) includes the indicator of motivation for "obtaining a diploma" ( $r=0.81)$ and self-evaluation of body slimness $(r=0.79)$. Fourth-year students' motivation for training is quite natural because they obtain a bachelor's degree at the end of the fourth year. In addition, it is not only training that is important to female students but also appearance, which is an essential gender trait. The factor is called the "motivation for obtaining a diploma". The fourth factor (7\%) consists of two main indicators: "motivation for mastering a profession" $(\mathrm{r}=0.73)$ and "attitude towards discipline of 'physical training'" $(r=0.65)$. Physical training serves as a basis for the formation of motivation for mastering professional skills of educational work with lower grade children. The factor is called the "motivation for mastering a profession". The fifth factor (9\%) includes three significant indicators: physical activity $(r=0.57)$, empathy for animals $(r=0.84)$ and empathy for children $(r=0.51)$. The empathy for animals is very likely to affect the formation of empathy for children in female students, especially because children's senses of kindness, compassion and caring for their neighbors are based on empathy for animals. We interpret this factor as "empathy for children". The sixth factor (11\%) includes indicators of physical fitness self-evaluation: athletic ability $(r=0.77)$, strength $(r=0.78)$, stamina $(r=0.69)$, which allows interpreting the factor as "physical fitness". The seventh factor $(10 \%)$ comprises four significant indicators: motivation for success $(r=0.71)$, empathy for parents $(r=0.79)$, seniors $(r=0.55)$, strangers and virtual strangers $(r=0.62)$. The negative relationship with empathy indicators can be viewed as limiting factors that suppress female students' motivation for success. Clearly, overprotection of relatives and seniors compromises the initiative of fourth-year female students, makes them less independent and focused on achieving success in their activities. This factor can be called the "motivation for success". The eighth factor $(7 \%)$ has one significant indicator: assessment of theoretical skills of students in physical training $(r=0.82)$.

Similarly to the factor structure of motivation of second-year full-time female students, the factor structure of motivation of second-year part-time female students has seven main components, but is slightly different. The first factor $(24 \%)$ is made up of indicators of physical development self-evaluation: coordination $(r=0.82)$, physical activity $(r=$ $0.75)$, athletic ability ( $r=0.87)$, global physical "me" ( $r=0.67)$, appearance $(r=0.72)$, strength $(r=0.70)$, flexibility $(r=0.77)$, and stamina $(r=0.83)$. All indicators are related to physical fitness, which is clearly essential for part-time female students because there is no compulsory discipline of "physical training". This factor is called "physical development". The second factor (12\%) includes three interrelated indicators: motivation for success $(r=0.83)$, self-evaluation of health $(r=0.83)$, and overall self-evaluation $(r=0.82)$. In our opinion, the interrelation of indicators indicates that the general level of physical activity affects the success in activities: the better the medical condition, the greater the motivation for success. This factor is interpreted as the "motivation for success". The third factor (8\%) comprises indicators of empathy for parents $(r=0.80)$, animals $(r=0.60)$ and characters from works of art $(r=0.54)$. Second-year part-time female students often share residence with their parents. Therefore, this indicator is attributed to the third factor, whereas it is attributed to the fifth and seventh factors in full-time female students. We verify this component as "empathy for parents". The forth factor (8\%) is represented by three indicators: motivation for acquiring knowledge $(r=0.76)$, mastering a profession $(r=0.71)$, and self-evaluation of body slimness $(r=0.60)$. These indicators are interrelated: female students with high self-evaluation of body slimness have low motivation to gain knowledge and master a 
profession. This reveals a gender trait in young girls where excessive focus on one's own figure and body mass reduces the motivation for training. This factor is called the "motivation for acquiring knowledge". The fifth major component (9\%) is characterized by empathy indicators where empathy for children is crucial $(r=0.88)$. The sixth factor $(6 \%)$ is mainly contributed by the assessment of theoretical skills of physical training $(r=0.90)$, as we call it. The seventh factor $(7 \%)$ is based on a positive attitude towards physical training ( $\mathrm{r}$ $=0.82)$, which propels the desire to obtain an academic degree $(r=0.56)$. The factor is interpreted as the "attitude towards physical training".

Fourth-year part-time training is also notable for its seven significant factors. The first factor (23\%) comprises nine indicators of physical development self-evaluation, namely health ( $\mathrm{r}$ $=0.62)$, coordination of movements $(r=0.71)$, physical activity $(r=0.70)$, athletic ability $(r=0.92)$, global physical "me" $(r=0.68)$, appearance $(r=0.76)$, strength $(r=0.77)$, flexibility $(r=0.68)$, and stamina $(r=0.71)$. All indicators have a positive interrelation and mainly characterize physical activity and physical fitness, which is more in demand among part-time students. We interpret this factor as "physical development". The second factor (11\%) involves the motivations for studying at the university. The interrelation of motivation indicators is characterized by the fact that the greater the motivation for obtaining a diploma $(r=0.86)$, the lower the motivation for acquiring knowledge $(r=0.61)$ and mastering a profession $(r=0.51)$. The focus on striving only to obtain a diploma adversely affects the motivation for success in activities $(r=0.66)$. The factor is called the "motivation for obtaining a diploma". The third factor $(9 \%)$ is based on indicators of empathy for children $(r=0.74)$, seniors $(r=0.81)$, and self-evaluation of body slimness $(r=0.54)$. The nature of interrelation of empathy indicators demonstrates that they help one another to form a kind, sensitive attitude towards both the younger and the older generation. The negative relationship with self-evaluation of body slimness may indicate that less slim female students have such properties of empathy, even with excess body weight. The factor is called the "empathy for children". The fourth factor (12\%) is marked by interrelations of indicators of self-evaluation of health $(r=0.53)$, body slimness $(r=0.62)$, global physical "me" $(r=0.53)$, overall physical development self-evaluation and attitude towards discipline of 'physical training'” $(r=0.76)$. Moreover, all interrelations are positive, which indicates a positive impact of physical training on the physical development of female students. This factor is called the "attitude towards discipline of 'physical training'". The fifth factor (8\%) has one key indicator: "empathy for parents" ( $r=0.92)$, which is interpreted likewise. The sixth factor (9\%) emphasizes the indicator for assessing theoretical skills in physical training that is specific to our research. According to interrelations, the quality of these skills is positively affected by empathy for animals $(r=0.77)$ and strangers and virtual strangers $(r=0.64)$, which contributes to the acquisition of these skills. The factor is called the "assessment of theoretical skills". The seventh factor $(6 \%)$ can be verified as the motivation for mastering a profession $(r=0.50)$ by empathy for characters from works of art $(r=0.81)$.

Furthermore, we confirmed this hypothesis using Kaiser's rule. Thus, the key factors determined by Kaiser's rule are those factors for which the eigenvalues of the correlation matrix are greater than one or close enough to it. The combination of selected factors generally explains $75 \%$ of the total data span for second-year full-time female students, $77 \%$ of the total data span - for fourth-year full-time female students, $74 \%$ of the total data span - for second-year part-time female students, $78 \%$ of the total data span - for fourthyear part-time female students.

The conducted analysis allows identifying features of the factor structure of motivational priorities for second- and fourth-year female students with different modes of attendance (see Table 1). All female students share a common factor of physical development selfevaluation, ranging from $16 \%$ to $27 \%$ of the overall dispersion contribution. 


\begin{tabular}{|c|c|c|c|c|c|c|c|c|}
\hline \multirow{4}{*}{ Factor name } & \multicolumn{8}{|c|}{ Mode of attendance } \\
\hline & \multicolumn{4}{|c|}{ Full-time } & \multicolumn{4}{|c|}{ Part-time } \\
\hline & \multicolumn{2}{|c|}{ 2nd year } & \multicolumn{2}{|c|}{ 4th year } & \multicolumn{2}{|c|}{ 2nd year } & \multicolumn{2}{|c|}{ 4th year } \\
\hline & 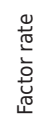 & 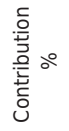 & 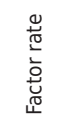 & 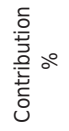 & 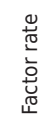 & 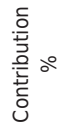 & 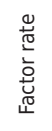 & $\begin{array}{l}\text { 들 } \\
\text { 总。 } \\
\text { 总 } \\
\text { cे }\end{array}$ \\
\hline Self-evaluation of physical development & 1 & 27 & I & 16 & I & 24 & 1 & 23 \\
\hline Attitude towards the discipline of "physical training" & II & 10 & - & - & VI & 7 & IV & 12 \\
\hline Motivation for success & - & - & III & 10 & II & 12 & - & - \\
\hline Motivation for acquiring knowledge & III & 9 & V & 9 & IV & 8 & - & - \\
\hline Empathy for parents & V & 8 & - & - & IV & 8 & V & 8 \\
\hline Empathy for strangers and virtual strangers & IV & 8 & - & - & - & - & - & - \\
\hline Empathy for children & VII & 6 & IV & 9 & III & 9 & III & 9 \\
\hline Motivation for "obtaining a diploma" & - & - & VI & 8 & - & - & II & 11 \\
\hline Motivation for "mastering a profession" & $\mathrm{VI}$ & 7 & VII & 7 & - & - & VII & 6 \\
\hline Physical fitness & - & - & II & 11 & - & - & - & - \\
\hline Assessment of theoretical skills in physical training & - & - & VIII & 7 & VII & 6 & VI & 9 \\
\hline
\end{tabular}

The indicators that make up the above factor are characterized by the fact that part-time training is dominated by indicators of physical development self-evaluation, athletic ability, physical qualities of strength, stamina, flexibility, coordination (i.e., physical fitness), which is lower than that in full-time training.

Another feature of the factor structure of the motivational sphere of female students is that the factor of "attitude towards discipline of 'physical training'" is peculiar to second-year full-time (10\%) and second- (7\%) and fourth-year (12\%) part-time female students.

It is commonly known that part-time female students have no practical classes in physical training, which means that the factor that serves as the basis for the motivational structure of training for female students from the Faculty of Primary Education indicates the need for such classes. Thus, the first factor includes significant indicators of physical fitness. This indicates the need for its improvement to achieve fitness for professional activities of a junior schoolteacher. The "motivation for acquiring knowledge" factor was noted in fulltime female students (9\%) and second-year part-time female students (8\%).

Fourth-year part-time female students do not have this motivation, as it is superseded by the motivation for obtaining a diploma (11\%). The "motivation for mastering a profession" factor was revealed in second- and fourth-year full-time female students (7\%) and fourthyear part-time female students (6\%). Fourth-year full-time female students and second- and fourth-year part-time female students (6-9\%) understand the importance of theoretical skills in physical training. For all modes of attendance, the "empathy for children" factor has a 6 to $9 \%$ contribution because it serves as the basis for professional fitness of a junior schoolteacher. The share of factors for motivational priorities of female students with different modes of attendance can serve as a basis for determining the organizational and methodological conditions for the formation of motivation for professional and applied physical training in female students from the Faculty of Primary Education. We specifically note the findings related to the performance indicators of part-time female students, where the curriculum does not provide practical classes in physical training, but their importance for the formation of professional fitness of a junior schoolteacher has been determined by female students themselves. 


\section{DISCUSSION}

The formation of non-special physical education of students from pedagogical universities is impossible without first considering the motivation of physical training activities, which is of great importance and serves as a major component and a core in fostering young people's positive attitude towards physical training classes.

Yarmak et al. [15-17] place great emphasis on the need to consider the motivational and axiological component for a successful educational process in physical training of students.

According to statistics, there are twice as many students up to the fourth year as the applicants with health issues. Compared to $24 \%$ of applicants assigned to the patient population during a medical examination, this group has increased to $40 \%$ during the first medical examination and up to $52 \%$ of the total number of examinations after the second medical examination. These data indicate that the number of students with health issues increases over the course of high school education [18-21].

Some researchers note that "the main problem of physical training in higher education is the students' need to achieve an optimal locomotor activity. This is possible only subject to the effective use of objective and subjective factors affecting the student's individuality. In this case, it is possible to maintain physical fitness of students at a sufficiently high level, $\square$ including both the medical condition and performance" [22].

Tsybulskaya, V. [25], who attempts to establish the relationship between physical activity and the cardiovascular system, notes that "physical activity is one of the necessary conditions of life, which has not only biological, but also social significance. Healthy young and middleaged people should spend 20-60 minutes walking, jogging, cycling, swimming, skiing, sports activities, etc. 3 to 5 times a week. Moreover, sessions should be quite intensive" [14].

Having investigated the medical condition of students from pedagogical universities using objective and subjective performance indicators and medical supervision statistics, Yarmak et al. [15] found that students with different modes of attendance have different selfevaluation of their own health: $28 \%$ of first-year students were reported to have perfect medical condition, as compared to $14 \%$ of second-year students, $19 \%$ and $15.6 \%$ of thirdand fourth-year students, respectively.

Moskalenko [10] found that junior schoolteachers start to feel mental and physical fatigue within 3-5 classes, as indicated by 51.6 and $56.6 \%$ of respondents, respectively. Fatigue mainly affects muscles of the back and legs, as noted in $83.4 \%$ of cases.

Studying the motivation to learn, we obtained new data that stand out from those already known [10]. The data of our research conducted with female students of the Faculty of Primary Education show that from the second to the fourth year the intramural female students' motivation to "gain knowledge" increases by $10.2 \%$ and "mastering the profession" by $11 \%$. By contrast, in extramural female students from the second to the fourth year, there is a decrease in the motivation to "master the profession" by $10 \%$. The difference in the motives for "gaining knowledge" and "mastering the profession" in fourth-year intramural female students is $7.8 \%$ and $26 \%$, respectively.

The results of our research confirmed the published data on the peculiarities of motivation for physical improvement of students $[6,8,18]$. Analysis of the answers to the questions of the methodology shows a decrease in motivation to learn for extramural female students to the fourth year, which is to some extent associated with a loss of confidence in choosing the right profession of primary school teacher due to hard work and low salaries. Our data are 
consistent with scientists' [10] conclusions on dropping interest in the study of fundamental disciplines of the curriculum and self-study of specialized subjects of extramural students. This thesis is also confirmed by the results of the analysis of the methods of determining the motivation for success.

Psychologists explain the different motivations for the chosen activity in terms of selfrealization of the individual. Tsybulskaya [25] introduces the term "life field of the individual", which is considered as a set of individual values, meanings and space of real activity - current and potential, covering the past, present and future. The past exists as experience, the future as a project, and the present as efficacy. These characteristics are in complex interaction with each other and, according to the psychologist, construct the individual's life field.

Liepina et al. [29] believe that the formation of physical self-improvement in students should be carried out through the organization of an outdoor camp both for the acquisition of knowledge and skills and for the development of professional competencies, as well as to promote outdoor skills, relationships and positive motivation.

The conclusions of our research indicate that important in the learning process for future teachers were the motives of "gaining knowledge" and "mastering professional skills". These findings seem to be consistent with other studies [30] that found that motivation to work, knowledge about activities, and practical performance are basic while studying in a higher education institution.

From these data, it becomes clear that teachers who work directly at school lack knowledge in physical training in terms of preservation of health. Therefore, students from pedagogical universities with different majors should be trained in physical education for them to avoid such problems in their future activities.

\section{CONCLUSION}

In this research, we found that for full-time female students between the second and the fourth year, the motivation for "acquisition of knowledge" and "mastering a profession" increases. However, part-time female students from the second to the fourth year, on the contrary, have a decrease in the motivation for "mastering a profession". These findings confirm the need to study the peculiarities of the formation of motivation of future teachers to physical improvement, which can improve their motivation to learn and professional self-improvement. Programs of physical improvement of future teachers should focus on the formation of components such as improving self-esteem of physical development, a positive attitude to the subject of "physical education", motivation for success, desire to obtain quality knowledge and education, formation of empathic attitude towards children, desire to master the profession of teacher.

\section{REFERENCES}

[1] Bolotin AE, Bakayev VV, Vazhenin SA. Educational technology of using the system of Pilates for the prevention of spine disorders of female students. J Phys Educ Sport. 2015;(4):724-729. https://doi.org/10.7752/jpes.2015.04110

[2] Andrieieva O, Hakman A, Balatska L, Moseychuk Y, Vaskan I, Kljus O. Peculiarities of physical activity regimen of 11-14-year-old children during curricular and extracurricular hours. J Phys Educ Sport. 2017;(4):2422-2427.

[3] Andrieieva O, Galan Y, Hakman A., Holovach I. Application of ecological tourism in physical education of primary school age children. J Phys Educ Sport. 2017;(1):7-15.

[4] Andrieieva O, Hakman A. Health status and morbidity of children 11-14 years of age during school. J Phys Educ Sport. 2018;Suppl2:1231-1236.

[5] Mokrova T, Bryukhanova N, Osipov A, et al. Possible effective use of Kangoo Jump complexes during the physical education of young students. J Phys Educ Sport. 2018;Suppl1:342-348. https://doi.org/10.7752/jpes.2018.s146

[6] Lubysheva LI, Gruznykh GM. Theoretical and methodological substantiation of physical training of students. Theor Practic Phys Train. 1991;6:9-12. 
[7] Kolomiytseva OE. Optimization of professional and applied physical training of students from secondary humanitarian educational institutions: Thesis ... for a Degree of Ph.D. in Physical Training and Sports. 24.00.02 - Physical Training, Physical Education of Different Social Groups. Kharkiv; 2006. 12.

[8] Fyshev Yu O, Lutsenko L, Shcherbak RM. Assessment of motivational factors for physical training of students. Slobozhansky Sci Sport Bull. 2012;3:164-169.

[9] Bezvernaya GV, Tsybulskaya VV. Peculiarities of empathy of female students with pedagogical majors. Slobozhansky Pedag Bull. 2014;4:5-8.

[10] Moskalenko NV, Sychova TV. Motivational priorities of students in physical education and sports. Sport Bull Dnieper Reg. 2012;2:10-14.

[11] Hakman A, Nakonechniy I, Moseychuk Y, Liasota T, Palichuk Y, Vaskan I. Training methodology and didactic bases of technical movements of 9-11-year-old volleyball players. J Phys Educ Sport. 2017;(4):2638-2642.

[12] Hakman A, Nakonechnyi I, Balatska L, Filak Y, Kljus O, Vaskan I. Peculiarities of physical and mental capacity of 6-9-year-old children under elementary school conditions. J Phys Educ Sport. 2018;Suppl2:1192-1198.

[13] Hakman A, Vaskan I, Kljus O, Liasota T, Palichuk Y, Yachniuk M. Analysis of the acquisition of expertise and mastery of physical skills for performing techniques by young footballers. J Phys Educ Sport. 2018;Suppl2:1237-1242.

[14] Hakman A, Andrieieva O, Bezverkhnia H, et al. Dynamics of the physical fitness and circumference sizes of body parts as a motivation for self-improvement and self-control in students. J Phys Educ Sport. 2020;20(1):116-122.

[15] Yarmak O, Blagii O, Palichuk Y, et al. Analysis of the factor structure of the physical condition of girls 17-19-yearold. J Hum Sport Exerc. 2018;Supplementary Issue: Spring Conferences of Sports Science. Costa Blanca Sports Science Week, 26-28 April 2018. Calpe. Alicante, Spain:259-268. https://doi.org/10.14198/jhse.2018.13.Proc2.11

[16] Yarmak O, Galan Y, Hakman A, Dotsyuk L, Blagii O, Teslitskyi Y. The use of modern means of health improving fitness during the process of physical education of student youth. J Phys Educ Sport. 2017;(3):1935-1940.

[17] Yarmak O, Galan Y, Nakonechnyi I, Hakman A, Filak Y, Blahii O. Screening system of the physical condition of boys aged 15-17 years in the process of physical education. J Phys Educ Sport. 2017:Suppl3:1017-1023.

[18] Tovt V, Mykhailovych S. Motivational Component of physical training of student youth. young sport science of ukraine: collection of studies in physical training and sports. Rev. 6: in 2 Vol. L.: Panorama Publishing, 2002;1:406-409.

[19] Maslow A. Motivation and Individuality. St. Petersburg: Piter, 2006.

[20] Zakharina EA. Formation of motivation for physical activity during physical training of students from higher educational institutions: Thesis ... for a Degree of Ph.D. in Physical Training and Sports. 24.00.02 - Physical Training, Physical Education of Different Social Groups. Kyev; 2008.

[21] Iedynak G, Galamandjuk L, Kyselytsia O, Nakonechnyi I, Hakman A, Chopik O. Special aspects of changes in physical readiness indicators of young men with different somatotypes between 15 and 17 years of age. J Phys Educ Sport. 2017;(4):2690-2696.

[22] Krusevich, T., Podlesny, O. Demand and motivational approach to organizing physical training of students. Theor Methodol PhysTrain Sport. 2008;2:69.

[23] Wells EK, Avery ML, Catanzarito BR, Wilson BN, Bunn JA. Assessment of breakfast and physical activity habits in college students at a rural private institution. J Phys Educ Sport. 2016;(3):770-775. https://doi.org/10.7752/ jpes.2016.03123

[24] Hakman A, Andrieieva O, Kashuba V, et al. Characteristics of biogeometric profile of posture and quality of life of students during the process of physical education. J Phys Educ Sport. 2020;20(1):79.

[25] Tsybulskaya V. Professional and applied physical training as part of physical education of pedagogical universities at the present stage. Physical Training of Children, Adolescents, Youth and Adults Nowadays: Proceedings of the 2nd International Research and Practice Online Conference. (Uman, April 10). - Uman: Visavi Publishing; 2014 , 176.

[26] Pasichnyk V, Pityn M, Melnyk V, Karatnyk I, Hakman A, Galan Y. Prerequisites for the physical development of preschool children for the realization of the tasks of physical education. Phys Activ Rev. 2018;6:117-126. https:// doi.org/10.16926/par.2018.06.16

[27] Physical Education: Curriculum for Ukrainian Higher Educational Institutions with Accreditation Level 3 and 4. Compiled by Raevsky RT, Tretyakov MA, Kanyshevsky SM.; Kyev; 2003.

[28] Balatoni I, Varga Szépné H, Müller A, et al. Sporting habits of university students in Hungary. Balt J Health Phys Activ. 2019;1(2):27-37. https://doi.org/10.29359/BJHPA.2019.Suppl.2.05

[29] Liepina I, Krauksta D. Students' attitude to and motivation for outdoor life. Balt J Health Phys Activ. 2014; 6(4):314321. https://doi.org/10.2478/bjha-2014-0031

[30] Nowak-Zaleska A, Zaleski R, Wilk B, Walentukiewicz A, Pasek M. Motivations for undertaking physical activity by first-year students of Faculty of Physical Education in 2000 and 2010. Balt J Health Phys Activ. 2014;6(1);41-47. https://doi.org/10.2478/bjha-2014-0005 